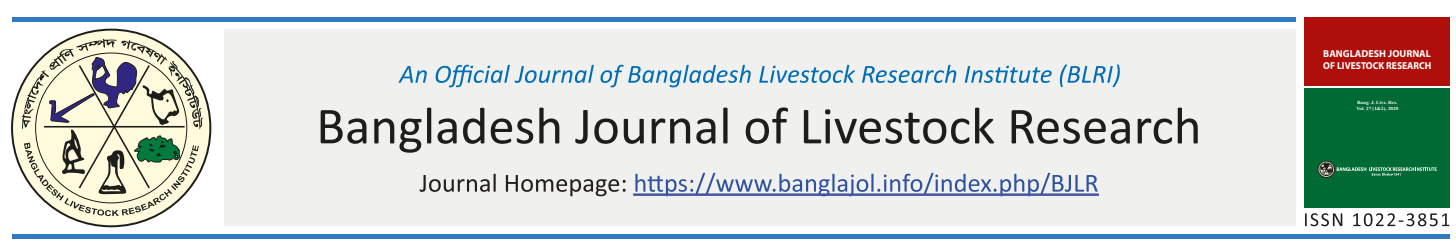

\title{
Detection of Brucella abortus during in vitro bovine embryo production
}

\author{
A. Akter ${ }^{1}$, G.K. Deb ${ }^{2 *}$, M.F.H. Miraz², M.A. Kabir², S.M.J. Hossain², M.R. Islam³ adn S.K. Dey ${ }^{4}$ \\ ${ }^{1}$ Beximco Pharmaceutical ltd, Dhaka; \\ ${ }^{2}$ Biotechnology Division, Bangladesh Livestock Research Institute, Savar, Dhaka 1341, \\ ${ }^{3}$ Bangladesh Agricultural Research Council, Farmgate, Dhaka 1342, Bangladesh and \\ ${ }^{4}$ Department of Microbiology, Jahangirnagar University, Savar, Dhaka 1342, Bangladesh.
}

\begin{abstract}
The in vitro embryo production (IVP) technology has emerged as a potential biotechnological approach to multiply genetically high yielding dairy cows. Its commercial application is increasing in many developed and developing countries over the years. Bangladesh livestock Research Institute (BLRI) adopted in vitro embryo production protocol from bovine ovaries of slaughterhouse. However, the risks of transmission of contagious diseases like Brucella abortus with embryos are not evaluated so far. Considering these facts, the present experiments were conducted to evaluate the efficiency of in vitro embryo production protocol with slaughterhouse ovaries as well as risk of contamination of produced embryos with Brucella abortus. To identify sources of contamination of embryos with Brucella abortus (if any), the laboratory water, different media used in the IVP process, semen, and follicular fluids were evaluated for confirmation of the organisms. In addition, vaginal swabs were collected from 2 buffaloes aborted due to suspected Brucella abortus infection. Molecular test were used to detect Brucella abortus contamination. Brucella abortus specific PCR product was not detected on agarose gel electrophoresis. The efficiency of IVP measured by cleavage and blastocyst development rates were $75.5 \pm 2.7 \%$ and $16.6 \pm 3.9 \%$, respectively. The present study inferred that the in vitro produce embryos are free from Brucella abortus infection.
\end{abstract}

Key words: In vitro embryo production, Brucella abortus, contamination, PCR

Bang. J. Livs. Res. Vol. 27 (1\&2), 2020: P. 105-112. https://doi.org/10.3329/bjlr.v27i1.55174

\section{Introduction}

In vitro embryo production (IVP) technology is a biological tool use for multiplication of population size of livestock in a short time. Application of this technology has grown rapidly science 2000 s and many large scale commercial farms are selling live embryo throughout the world (Moore and Hasler, 2017). The International Embryo Transfer Society (IETS) recommended evaluation of IVP embryos for contagious diseases before transfer to recipients. However, according to

*Corresponding author: debgk2003@yahoo.com 
World Organization for Animal Health, IVP embryos are prone to contaminate with Brucella abortus, Campylobacter fetus (subs. veneralis), Mycobacterium paratuberculosis, Mycobacterium bovis, Chlamydia psittaci, Trichomonas fetus, and Bovine viral diarrhoea virus (Yohannes et al., 2012). Among above diseases, Brucella abortus is more virulent as it causes about 90\% abortion in bovine species (Blood and Handerson, 1971). Presence of these bacteria in any stages of IVP may results potential hazard for recipient animals and as well as may causes zoonosis.

In Bangladesh, brucellosis is endemic and infection cases in humans and animals were reported (Rahman et al., 2011, Islam et al., 2019). Prevalence of brucellosis in cattle, buffalo, goats and sheep were $3.7 \%, 4.0 \%$, $3.6 \%$ and $7.3 \%$ respectively in Bangladesh (Islam et al., 2013). The disease may constitute a considerable impact on human and animal health as well as on socioeconomic factors and it might be a significant drawback in the development of the livestock sector (Rahman et al., 2011). Hence, the control measure of animal brucellosis is associated with reduced public risk of exposure (WHO, 2006). There are different biochemical and molecular methods are available to detect Brucella abortus contamination. However, molecular identification using polymerase chain reaction $(\mathrm{PCR})$ is the most reliable methods for detection of Brucella spp. (Kulakov et al., 1992). Considering these facts present study was conducted to identify the presence of Brucella abortus to assess the sanitary status of in-vitro embryo production system in Bangladesh condition.

\section{Materials and Methods}

\section{Study place}

The research was conducted in the Reproductive Biotechnology laboratory of Biotechnology Division and Bacteriology laboratory of Animal Health Research Division, Bangladesh Livestock Research Institute (BLRI), Savar, Dhaka-1341.

\section{In vitro embryo production (IVP)}

Ovaries of slaughtered cows were collected from abattoir located at Mohammodpur, Dhanmondi, Dhaka for IVP embryo production. The IVP protocol was described in previous report (Deb et al., 2016). In brief, 10 cumulus-oocyte-complexes (COC) aspirated from 3 to $8 \mathrm{~mm}$ diameter follicles of slaughtered cow ovaries were selected for in vitro maturation (IVM). The selected COC were washed 2-3 times in TL-HEPES followed by 2-3 times washing in IVM medium before placing them into $120 \mu \mathrm{L}$ droplet of IVM medium. The matured COC were fertilized in vitro (IVF) using fresh semen capacitated through incubation with heparin sodium salt $(20 \mu \mathrm{g} / \mathrm{mL})$ dissolved in the IVF medium for $15 \mathrm{~min}$. The capacitated sperm were diluted at approximately ${ }^{1 \times 106}$ spermatozoa/mL with IVF medium. The matured $\mathrm{COC}$ were co-cultured with capacitated spermatozoa for 18 to $20 \mathrm{~h}$. After IVF, cumulus cells were removed by gentle pipetting into TL-HEPES. The denuded zygotes were washed in in vitro culture (IVC) medium-I (3 times) and placed them into the culture droplet for 3 days. After 3 days, the 8 to 32 cell embryos were transferred into ICV-II medium for remaining culture period (until Day 8). The incubation conditions during IVM, IVF, and 
IVC were $5 \% \quad \mathrm{CO}_{2}$ in air at $38.5^{\circ} \mathrm{C}$ temperature with maximum humidity. Cleavage development rates were evaluated at day 3 (day 0: day of IVF) as a proportion of the presumed zygote transferred into IVC-I medium. Blastocyst development rates were calculated at Day 8 as a proportion of the presumed zygote transferred into IVC-I medium. IVP was conducted in six batches.

\section{Evaluation of Brucella abortus contamination in IVP procedure}

For detection of Brucella abortus infection during bovine IVP, samples were collected from six independent batches of IVP experiment. Laboratory produced blastocyst, the laboratory water, TL-HEPES, Dulbecco's phosphate buffer saline, in vitro maturation medium, in vitro fertilization medium, in vitro culture medium I and II, follicular fluid and semen used for IVP was simultaneously analyzed for detection of Brucella abortus. Vaginal swabs collected from two aborted buffaloes (abortion was taken place during 6-7 months of pregnancy) were used as susceptive positive control for Brucella abortus. The clinical symptoms of aborted buffaloes resembled with Brucella infected buffalo symptoms. Moreover, extracted genomic DNA was collected from Bangladesh Agricultural University, Mymensingh as a known positive control for molecular confirmation of Brucella abortus. The vaginal swabs were diluted in $200 \mu \mathrm{l}$ phosphate buffer saline solution. Initially all samples $(50 \mu \mathrm{L} /$ plate $)$ were plated into bacteriological nutrient agar media for 48 hours at $37^{\circ} \mathrm{C}$ in a humidified condition. If bacterial colonies were grown into the nutrient agar plate, then the colonies were streaked onto the Kuzdas and Morse selective agar media (Oxoid, UK) and incubated for 72 hours at $37^{\circ} \mathrm{C}$. The media was sterilized in an autoclave at $121^{\circ} \mathrm{C}$ with 15 psi pressure for $15 \mathrm{~min}$ before streaking of colonies. Colonies developed into Kuzdas and Morse selective agar medium were sub-cultured on nutrient agar plate overnight and samples were taken for molecular characterization.

\section{Molecular identification}

Genomic DNA was isolated from bacterial colonies using the Wizard Genomic DNA Purification Kit (Promega, USA) according to the manufacturer's instruction. Isolated DNA was quantified by Nanodrop 2000c (Thermo Scientific). Concentration of extracted DNA was 22.2 to 35.6 nanogram/ $\mu$ l. The PCR was conducted using two sets of previously designed primers (Table 1). PCR reactions were performed using a thermal cycler (Hain Life Science, Germany). The final volume for amplification was $15 \mu \mathrm{L}$, containing $1.5 \mu \mathrm{L}$ of $10 \mathrm{X}$ reaction buffer, $0.45 \mu \mathrm{L}$ of dNTPs, $0.15 \mu \mathrm{L}$ of Taq polymerase, $2 \mu \mathrm{L}$ of DNA, 1 $\mu \mathrm{L}$ of 10 pmol forward primer, $1 \mu \mathrm{L}$ of 10 pmol reverse primer and $7.7 \mu \mathrm{L}$ of PCR water (DNase, RNase, and Protease free water). The reaction mixture was first denatured by heating at $94^{\circ} \mathrm{C}$ for 1 minute, followed by 30 cycles of denaturation at $94^{\circ} \mathrm{C}$ for 1 minute, annealing at $54^{\circ} \mathrm{C} / 60^{\circ} \mathrm{C}$ for 1 minute and extension at $72^{\circ} \mathrm{C}$ for 1 minute. At the end of cycles, the reaction mixture was maintained at $72^{\circ} \mathrm{C}$ for 5 minutes. The PCR products were loaded into a $1.5 \%$ agarose gel containing $1 \mathrm{X}$ TAE (Tris- Acetate-EDTA) buffer at 90 volts for 60 minutes. The gel was stained with ethidium bromide before photographed using ultraviolet illumination. 
Table 1. Primers sequences used for the amplification

\begin{tabular}{l|l|l|l|l}
\hline $\begin{array}{l}\text { Gene } \\
\text { name }\end{array}$ & Oligonucleotide Sequence $\left(5^{\prime}-3^{\prime}\right)$ & $\begin{array}{l}\text { Product } \\
\text { size (bp) }\end{array}$ & Ta & Reference \\
\hline $\begin{array}{l}\text { alkB } \\
\text { and } \\
I S 711\end{array}$ & F: CCATTGAAGTCTGGCGAGC & 157 & $54^{\circ} \mathrm{C}$ & Doust et al., 2007 \\
\hline $\begin{array}{l}\text { omp- } \\
2\end{array}$ & F: GCGCTCAGGCTGCCGACGCAA & 193 & $60^{\circ} \mathrm{C}$ & $\begin{array}{l}\text { Leal-Klevezas et al., } \\
1995\end{array}$ \\
\hline
\end{tabular}

*bp: base pair, F: forward; R: Reverse; $\mathrm{Ta}=$ Annealing temperature

\section{Results}

\section{In vitro embryo production}

The in vitro embryo production efficiency up to cleavage and blastocyst were shown in Table 2. Among the cultured oocytes, $75.5 \pm 2.7 \%$ was cleaved and among the cleaved embryos $16.6 \pm 3.9 \%$ were developed to blastocyst stage. colony and both vaginal swabs yielded yellow colonies (Figure 1). These isolates initially presumed as Brucella abortus. Because Brucella abortus developed characteristics pale yellow to yellow colonies. However, upon PCR with Brucella abortus specific primers, Brucella abortus specific PCR product was not detected on agarose gel electrophoresis (Figure 2).

Table 2. In vitro embryo development efficiency in conventional droplet culture system

\begin{tabular}{c|c|c}
\hline Replication number & \% cleaved (Mean \pm SE) & \% Blastocyst (Mean \pm SE) \\
\hline 6 & $75.5 \pm 2.7 \%$ & $16.6 \pm 3.9 \%$ \\
\hline
\end{tabular}

\section{solation and identification of Brucella abortus}

No bacterial colonies were grown on nutrient agar medium plate for laboratory water, different media used in the IVP procedure (IVM, IVF, IVC and IVC-II medium, TL-Hepes and Dulbicos phosphate buffer saline), semen used for IVF and blastocyst developed during IVP. Bacterial colonies were observed in one set of follicular fluid out of total seven set samples and in two vaginal swabs samples collected from aborted buffaloes. These bacterial isolates were also grown on Kuzdas and Morse selective agar medium. Isolates from the follicular fluid yielded pale yellow
These results indicated that the suspected isolates were not Brucella abortus.

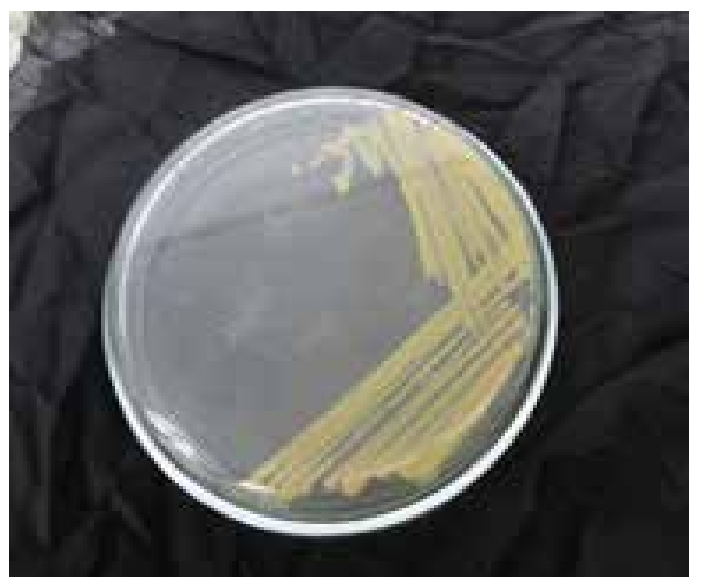

Figure 1. Representative photograph showing suspected Brucella abortus colony on Kuzdas and Morse selective agar medium 


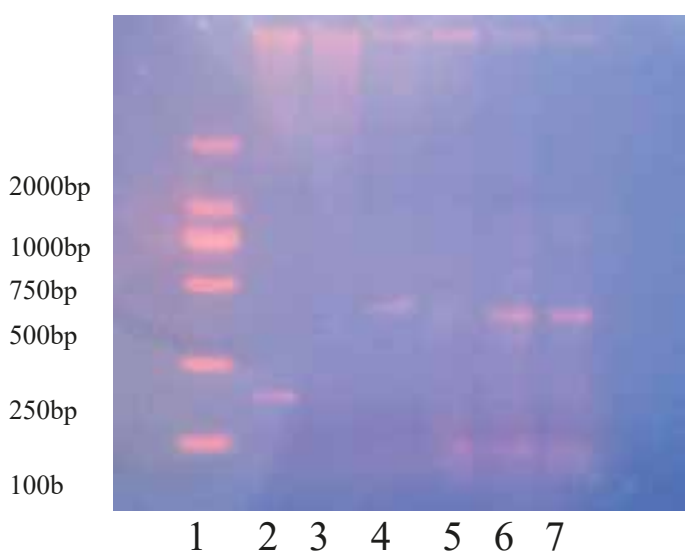

Figure 2. Representative photograph showing electrophoresis profile of amplified presumed B. abortus DNA. Lane 1: DNA Marker (DL 2000), lane 2: positive control (Genomic DNA of B. abortus), lane 3: Negative control (Escherichia coli DNA), lane 4: Follicular fluid, lane 5: Blastocyst, lane 6: Aborted buffalo sample-1, lane 7: Aborted buffalo sample-2.

\section{Discussion}

The in vitro embryo production technology (IVP) is adopting with traditional selective cattle breeding gramme to increase genetic progress in many developed and developing countries. The current oocyte collection followed by their in vitro maturation, in vitro fertilization, in vitro culture and embryo transfer to recipient have improved much to support commercial application of the IVP. Bangladesh Livestock Research Institute (BLRI) has also adopted IVP technology (Deb et al., 2016). The present study reported embryonic development rates to cleavage and to blastocyst stage at BLRI are $75.5 \pm 2.7 \%$ and $16.6 \pm 3.9 \%$ respectively. Results also showed that the slaughterhouse produced bovine IVP embryos are free from Brucella abortus infection.

In general, cleavage rates are 70 to $85 \%$ and blastocyst development rates are 30 to $50 \%$ during IVP (Dey et al., 2011, Deb et al., 2011). The cleavage rate found in this study is within normal range. The maternal factors an oocyte carrying from its follicle largely influence its development to cleavage stage. Moreover, culture condition, media and other factors have less influence on cleavage. This study is reporting low blastocyst development rate compared to normal range of blastocyst development. However, cleavage and blastocyst development rate is little improved than our previous report (Deb et al., 2016). Several factors including oocyte donor, oocytes handling, semen quality, culture media, culture conditions, osmolality of media, $\mathrm{CO}_{2}$ level of incubator and water quality used for glassware cleaning, media preparation and others steps of IVP influences the rate of blastocyst development (Fukuda et al., 1987, Gordon, 1994, Brum et al., 2005). The International Embryo Transfer Society (IETS) recommended evaluation of IVP embryos for contagious diseases before transfer to recipients. The IVP embryos are sometimes reported to be contaminated with different microorganisms. According to OIE (2012) IVP embryos are prone to contaminate with Brucella abortus, Campylobacter fetus (subs. veneralis), Mycobacterium paratuberculosis, Mycobacterium bovis, Bovine viral diarrhea virus, Chlamydia psittaci and Trichomonas fetus among others. Bovine brucellosis, a serious zoonotic disease manifested by reproductive disorders is resulting huge economic losses to dairy farmers (Cooper, 1991; Radostits et al., 2000; Singh et al., 2002). Control measure of animal brucellosis is associated with reduced public risk of exposure (WHO, 2006; Zinsstag et al., 2007). 
The present study evaluated Brucella abortus contamination of BLRI developed bovine IVP blastocysts and the different raw materials (laboratory water, culture media and follicular fluid) used during this process. No bacterial colonies were observed during culture of different samples related to IVP except one replicate of follicular fluid. This results indicted proper hygienic condition of IVP. Neglia et al. (2007) reported production of Brucella abortus free in vitro buffalo embryos from a confirmed naturally Brucella abortus infected buffalo ovary. Oocyte and follicle collected from naturally (Barrios et $a l ., 1988$ ) or artificially (Stringfellow et al., 1988) Brucella abortus infected cows were free from the organism. Bielanski and Surujballi, (1998) reported that antibiotic used in IVM, IVF and IVC media prevent contamination of major bacteria, virus and others agents. Moreover, Brucella abortus contamination of embryos can be eliminated through ten times washing of embryos with D-PBS containing penicillin (100 IU/mL) and streptomycin $(100 \mu \mathrm{g} / \mathrm{mL})$ (Jacques et al., 2004; Mallek et al., 1988). During this study, penicillin $(100 \mu \mathrm{g} / \mathrm{mL})$ and streptomycin $(100 \mu \mathrm{g} / \mathrm{mL})$ were used in every stages of IVP that prevents the possible risk of contamination (if any).

Bacterial colonies grown on nutrient agar for one replicate of follicular fluid and two aborted buffalo's vaginal swabs were also grown on Kuzdas and Morse selective agar plate. Isolate from the follicular fluid yielded pale yellow colony and both vaginal swabs yielded yellow colonies. Brucella abortus developed characteristics pale yellow to yellow colonies on selective medium. Hence, these three isolates were preliminary presumed as Brucella abortus. Molecular identifications of the collected 3 isolates were done through PCR using two sets of pre-used primers. First set of primer amplified Brucella abortus specific gene alkB and IS711 (Doust et al., 2007) and that of second set amplified omp-2 gene (Leal-Klevezas et al., 1995). No Brucella abortus specific PCR product on agerose gel electrophoresis was detected, which indicated that the isolated colonies were not actually Brucella abortus. To validate this result, same primer sets were also used for PCR with known DNA of Brucella abortus collected from Bangladesh Agricultural University and yielded expected band size. These results collectively suggest that the isolated colonies were not Brucella abortus. Presumptive Brucella abortus isolated from aborted buffalo cow's swabs did not pass molecular confirmation study. The abortion might be caused by other reproductive disease causing organisms possessing similar morphological, biochemical and cultural properties with Brucella abortus, or due to other reasons of abortion.

The present findings inferred that the in vitro embryo production protocol of BLRI support normal cleavage and blastocyst development and developed blastocysts are free from Brucella abortus.

\section{References}

Barrios, D.R., Kraemer, D.C., Bessoudo, E. and Adams L.G.1988. Failure to isolate Brucella abortus from embryos or ova from culture-positive super ovulated cows. Theriogenology. 29: 353-361.

Blood, D.C.; Handers, J.A. 1971. Diseases caused by Brucalla spp.Veterinary Medicine 3rd edition. Bailliere T indall and Cassell, London. pp:787. 
Brum, D.S.; Leivas, F.G.; Silva, Rauber, L.P.; Fialho, S.S. 2005. The effects of number of oocytes and the volume of maturation medium in bovine in vitro embryo production. Ani. Repro. 2: 70- 73.

Cooper, C. W. 1991. The epidemiology of human brucellosis in a well defined urban population in Saudi Arabia. J. Tropical Medi. Hygiene. 94(6):416-22.

Deb, G.K.; Dey, S.R.; Nahar, T.N.; Khan, M.Y.A.; Rahman, M.M. 2016. In vitro production of bovine blastocyst with oocyte collected from abattoir ovary. Bangladesh J. Ani. sci. 45(1): 31-35

Deb, G.K.; Jin, J.I.; Kwon, T.H.; Choi, B.H.; Cho, S.J.; Bang, J.I.; Dey, S.R.; Ch, I.R.; Kong, I.K. 2011. Improved blastocyst development of single cow OPU-derived presumptive zygotes by group culture with agarose-embedded helper embryos. Repro. Biol. Endocrinol. 9:121.

Dey, S.R.; Deb, G.K.; Ha, A.N.; Lee, J.I.; Bang, J.I.; Lee, K.L.; Kong, I.K. 2011. Co-culturing denuded oocytes during the in vitro maturation of bovine cumulus oocyte complexes exerts a synergistic effect on embryo development. Theriogenology. 7:1064-77.

Doust, S.R.H.; Ahmadi, Z.; Ahamdi, A.; Izadi, M.H.M.; Mobarez, A.M. 2007. Detection of Brucella abortus by alkB and IS711 based primers. Journal of Res. Medical Sci.12 (2):62-67.

Fukuda, A.; Noda, Y.; Tsukui, S.; Matsumoto, H.; Yano, J; Mori, T. 1987. Influence of water quality on in vitro fertilization and embryo development for the mouse. J. In Vitro Fertilization Embryo Transfer. 4: 40-45.
Gordon, I. 1994. Laboratory Production of Cattle Embryo. CAB International, Wallingford, Oxon OX 108 DE, UK.

Islam, M. A; Khatun, M. M.; Werre, S. R.; Sriranganathan, N.; Boyle, S.M. 2013. A review of Brucellaseroprevalence among humans and animals in Bangladesh with special emphasis on epidemiology, risk factors and control opportunities. Vet. Microbiol. 166:317-326.

Islam, M.S; Garofolo, G; Sacchini, L; Dainty, A.C; Khatun, M.M; Saha, S; Islam, M.A. 2019. First isolation, identification and genetic characterization of Brucella abortus biovar 3 from dairy cattle in Bangladesh. Veterinary Medicine and Science. 5:556-562.

Jacques, M. Grayon, F. Berthelot, B. Garin-Bastuji, L.A. Guilloteau, F. Martinat-Botté. Risk of a brucell transmission by porcine embryos: an in vivo study. International Society for Animal Hygiène - Saint-Malo: 129-130.

Kulakov, Y. K.; Gorelov, V. N.; Motin, V. L.; Brukhanskii, G. V. ; Skavroskaya A. G.1992. A highly sensitive nonisotopic DNA hybridization system using amplification (PCR) for the identification and indications of Brucella. Molecular Genetics, Microbiol. and Virolo. 7(8):23-27.

Leal-Klevezas, D.S.; Martínez-Vázquez, I.O.; López-Merino,A.; Martínez-Soriano, J. P.1995. Single-step PCR for detection of Brucella spp. from blood and milk of infected animals. J. Clinical Microbiol. 33(12):3087- 3090 
Mallek, Z., Guérin B., Nibart M., Parez M. and Thibier M.1984. Effects of Brucella abortus contamination in vitro of mouse and cows embrys. Bulletin Acad. Vét. France. 57: 479-490.

Moore, S.G. and Hasler, J. F.2017. A 100-Year Review: Reproductive technologies in dairy science. Journal of Dairy Science. 100:10314-10331.

Neglia, G.; Zicarelli, L.; Di Palo; Picillo, E.; Attanasio, L.; Boccia,L.; Gasparrini, B.; De Rosa, Pepe T.; Gravino, A.E.; Iovane, G.; Buonavoglia, C.; Manna, L. 2007. Brucella DNA is not detected in in-vitro produced embryos derived from ovaries of naturally infected buffaloes. Italian J. Anim. Sci. 6:sup2: 900-903.

OIE. 2012.Terrestrial animal health code Brucellosis, http:/www.oie.int.

Radostis, O.M.; Gaycc, D.c.; Hinchcliff, K.W. 2000. Veterinary medicine: A textbook of the diseases of cattle, sheep, pig, goats and horses. W.B. Sanders, London. 9 th Ed.18-77.

Rahman, M.S; Faruk, M.O; Kim, J.Y; Kang,S.I; Jung, S.C. 2011. Prevalence of brucellosis in ruminants in Bangladesh. Vet. Med. 56 (8): 379-385.

Singh, E.L. 2002. The diseases control potential of embryos. Theriogenology. 27:9-20.

Stringfellow, D.A., Wolfe, D.F., Lauerman, L.H., Sparling, P.H.1986. Resistance of preimplantation bovine embryos to infection with Brucella abortus. American J. Vet. Res. 47: 1924-1927.

World Health Organization (WHO). 2006. Brucellosis in humans and animals. Geneva, Switserland: WHO Press

Yohannes, M.; Gill, J.P.S.; Ghatak, S.; Singh, D.K.; Tolosa, T. 2012. Comparative evaluation of the Rose Bengal plate test, standard tube agglutination test and complement fixation test for the diagnosis of human brucellosis. Revue scientifique et technique (International Office of Epizootics). 31 (3): 979-984.

Zinsstag, J.; Schelling, E.; Roth, F.; Bonfoh, B.; Savigny, D.;Tanner, M. 2007. Human Benefits of Animal Interventions for Zoonosis Control. Emerging inf. dis. 13(4):527-31. 